\title{
Laparoscopic Pancreatic Enucleation With End-to-End Pancreatic Duct Reconstruction
}

\author{
Takashi Kokudo, MD, David Petermann, MD, Nicolas Demartines, MD, and Nermin Halkic, MD \\ Department of Visceral Surgery, University Hospital CHUV, Lausanne, Switzerland
}

\begin{abstract}
Background. Laparoscopic enucleation for neuroendocrine pancreatic tumors has become a feasible technique, with a reported incidence of pancreatic fistula ranging from 13 to $29 \% .^{1-3}$ This report describes the first successful case of laparoscopic pancreatic enucleation with resection of the main pancreatic duct followed by end-to-end anastomosis.

Methods. A 41-year-old woman was admitted to the authors' hospital for repeated syncope. Hypoglycemia also was noted. A contrast-enhanced computed tomography examination showed a highly enhanced tumor measuring $22 \mathrm{~mm}$ in diameter on the ventral side of the pancreatic body adjacent to the main pancreatic duct. The patient's blood insulin level was elevated, and her diagnosis was determined to be pancreatic insulinoma. Laparoscopic pancreatic enucleation was performed. Approximately $2 \mathrm{~cm}$ of the main pancreatic duct was segmentally resected, and a short stent (Silicone tube: Silastic, Dow Corning Corporation, Midland, MI) was inserted. The direct anastomosis of the main pancreatic duct was performed using four separate sutures with an absorbable monofilament (6-0 PDS).
\end{abstract}

Results. The operation time was $166 \mathrm{~min}$, and the estimated blood loss was $100 \mathrm{~mL}$. The postoperative course was uneventful, and the patient was discharged from hospital on postoperative day 7. The pathologic findings showed a well-differentiated insulinoma and a negative surgical margin. A computed tomography examination performed 1 month after the operation showed a successful anastomosis with a patent main pancreatic duct.

Conclusions. Laparoscopic segmental resection of the main pancreatic duct and end-to-end anastomosis can be performed safely with the insertion of a short stent. This technique also can be used for a central pancreatectomy.

DISCLOSURE No support was received for this research. The authors have no competing interests to declare.

\section{REFERENCES}

1. Dedieu A, Rault A, Collet D, Masson B, Sa Cunha A. Laparoscopic enucleation of pancreatic neoplasm. Surg Endosc. 2011; 25:572-6.

2. Fernández-Cruz L, Molina V, Vallejos R, Jiménez Chavarria E, López-Boado MA, Ferrer J. Outcome after laparoscopic enucleation for nonfunctional neuroendocrine pancreatic tumours. $H P B$. 2012;14:171-6.

3. Subar D, Gobardhan PD, Gayet B. Laparoscopic pancreatic surgery: an overview of the literature and experiences of a single center. Best Pract Res Clin Gastroenterol. 2014;28:123-32.
Electronic supplementary material The online version of this article (doi:10.1245/s10434-014-4188-2) contains supplementary material, which is available to authorized users.

(C) Society of Surgical Oncology 2014

First Received: 21 June 2014;

Published Online: 29 October 2014

N. Halkic, MD

e-mail: nermin.halkic@chuv.ch 